\title{
LA DEMOCRACIA LOCAL: ENTRE EL ESPEJISMO NEOTOCQUEVILLISTA Y LA GLOBALIZACIÓN ${ }^{*}$
}

BERNARD JoUve

UNIVERSIDAD DE QuÉBEC, CANADÁ

\begin{abstract}
Resumen
Desde hace quince años aproximadamente, la literatura sobre la gobernanza y la democracia local se ha multiplicado. En un contexto de importantes transformaciones del Estado en las democracias occidentales y de desconfianza ostensible por parte de la sociedad civil hacia la esfera de lo político, se considera muy a menudo el nivel local como la matriz a partir de la cual es posible refundar el vínculo político en una agenda participativa y menos centrada en los personajes políticos. Este artículo tiene por objetivo evaluar "el impacto" de la democracia participativa en la transformación del orden político. Para ello se focaliza en el cuestionamiento aparente del carácter central de los representantes elegidos, sobre el alcance de las políticas de habilitación y sobre las transformaciones de la ciudadanía.
\end{abstract}

Abstract

Since the early nineties, the literature on governance and local government has grown exponentially. In a context of deep transformations of the State in Western democracies and an evident distrust of civil society towards the political sphere, the local dimension is considered the matrix from which it is possible to rebuild, with a smaller attention on political personages, a political bond centered on a participative agenda. The objective of this article is to evaluate the impact of participative democracy in the transformation of the political order. In doing so, it inquires on the central character of the elected representatives on the scope of policies and transformation of citizenship.

PALABRAS CLAVE • Governance • Local Democracy • Citizenship • Political Participation • Empowerment

\section{INTRODUCCIÓN}

Los debates sobre la democracia local, en una agenda participativa, toman cuerpo en sociedades en las cuales la relación entre la sociedad civil y lo político se descompone progresivamente (Skocpol, et al., 1999). Más exactamente, es un tipo de organización de lo político asociado con el cuestionamiento de la primera modernidad (Beck, 1998). En efecto, ha sido inconcebible duran-

Este articulo se inscribe en el marco de la investigación Gobernanza metropolitana y competitividad international: los ejemplos de Montreal y Toronto, financiada por el Consejo de Investigación en Ciencias Humanas de Canadá (\#4102003-1207). Este artículo fue traducido por Felipe de Alba. 
te mucho tiempo pensar lo político fuera del Estado, de sus instituciones y de su territorio controlado por medio de un conjunto de fronteras y de instrumentos normativos. Este modelo político parece haber tenido su tiempo o por lo menos es cuestionado.

Es en este contexto general de "crisis" de la primera modernidad centrada en el Estado -y en la representación como principio de agregación de las preferencias individuales formadoras de una comunidad política-, donde observamos el desarrollo de un conjunto de discursos y prácticas que reconocen la importancia de la democracia local, con características participativas.

Más precisamente, estos discursos y prácticas ponen de antemano la adaptación de los representantes elegidos a las dificultades nuevas que pesan sobre ellos y que justifican el recurso cada vez más sistemático a la concertación, a la participación, a la deliberación en la elaboración y la aplicación de las políticas públicas (Blondiaux et al., 2002). Este artículo tiene por objetivo, precisamente, intentar una evaluación del alcance de estos discursos y prácticas sobre la transformación del orden político.

Desde hace varios años, asistimos también a un incremento considerable, tanto en el campo de lo político como en la esfera académica, de las reflexiones sobre la democracia local y la gobernanza. Esencialmente, se sostiene la hipótesis general -o incluso el postulado- de que los regímenes políticos contemporáneos tienen una tendencia clara a la pluralización. El espacio local se convierte en un terreno de observación privilegiado de esta dinámica, en la cual se cuestionan el rol de los políticos electos y el de la democracia representativa. No obstante, como lo sostiene G. Hermet,

Solo damos vueltas en círculos, sin responder de manera sustancial a las preguntas sobre la relación del concepto de gobernanza con la democracia, a lo sumo, en lo que a mí concierne, me consuela que esta niebla de palabras haga resurgir en mi espíritu las dos cuestiones primordiales que Aristóteles colocaba sobre el ejercicio de la política como poder. Primera cuestión: ¿cuál es el mejor gobierno? Segunda cuestión: quién tiene derecho de gobernar (Hermet, 2004 : 159).

Sin pretender responder a estas preguntas clásicas, este artículo se fija como objetivo explicar los procesos sociopolíticos e institucionales de lo (re)nuevo de la democracia local, en su modo participativo. Se trata también de intentar definir "el impacto" de la democracia participativa en la transformación del orden político establecido en las democracias modernas sobre la figura central de la autoridad elegida.

Este artículo trata también de la ampliación de esta agenda participativa desde los campos de la política local hasta quedar en manos de las instituciones públicas: el desarrollo económico. Particularmente, se hablará de las políticas de fortalecimiento (empowerment) de algunos grupos sociales y de las relaciones que existen entre estas políticas de responsabilización de grupos sociales localizados, por medio de la participación, y la transformación del Estado keynesiano.

La conclusión abarca el vínculo entre estas prácticas democráticas que se desarrollan en el nivel local, esencialmente en el medio urbano, y la transformación de la ciudadanía en su versión liberal y universalista en el seno de sociedades cada vez más divididas y que son objeto de reivindicaciones en favor "del derecho a la diferencia" (cultural, de clase, religiosa, racial...) de algunos grupos sociales. Desde un punto de vista metodológico, este artículo se fundamenta en la movilización de un corpus bibliográfico que contempla estas tres cuestiones en Norteamérica y en Europa del Occidental. 


\section{LA CRISIS DE LO POLÍTICO Y EL CUESTIONAMIENTO DE LA PRIMERA MODERNIDAD}

A mediados de los años setenta, se habían definido las primeras señales de agotamiento de un método de organización de lo político, calificado como Estado-central. En un informe que pasó a la posteridad, M. Crozier, S. Huntington y J. Watanuki mencionaban entonces una "crisis de las democracias" occidentales que se expresaba, esencialmente, en la incapacidad del Estado para responder al conjunto de demandas sociales que recibía. La "sobrecarga" del aparato de Estado generaba una incapacidad de acción y, por lo tanto, un cuestionamiento de su legitimidad funcional (Crozier et al., 1975). En los años ochenta, teniendo como fondo la "revolución conservadora" en los Estados Unidos y en Gran Bretaña, el tema de la "crisis" desaparece un tiempo del orden del día. La recurrencia a programas liberales basados en la desregulación y la privatización explica en parte esta evolución.

No es sino a mediados de los años noventa cuando se menciona de nuevo la "crisis de las democracias modernas" causada por la globalización, la recomposición de los Estados y por transformaciones sociológicas profundas. La terminología también cambia. La "crisis de las democracias modernas" se transforma en "crisis de gobernabilidad" que requiere nuevas herramientas de gobernanza (Kooiman, 1993). Este cambio semántico permite hacer hincapié en el hecho de que la "crisis" no es solamente funcional y no se expresa solamente en términos de "sobrecarga" del aparato de Estado, sino, básicamente, en el marco de un doble cuestionamiento. Por una parte, de las condiciones mismas de producción de las políticas públicas y, por otra, de la legitimidad del poder público. En los hechos, las dinámicas que alimentan este doble cuestionamiento aparecen desde los años sesenta. En particular, se puede mencionar:

- El cuestionamiento de un modo de ejercicio de lo político que se basa en la soberanía (Mayer, 2000);

- $\quad$ el carácter central, por una parte, de los partidos políticos como instancias que incorporan las preferencias de los individuos y, por otra, el desmoronamiento de las fidelidades electorales (Pharr et al., 2000);

- la crítica de un modo de agregación de las preferencias basado en la legitimidad legalracional monopolizada por el Estado y sus administraciones (Habermas, 1997);

- el proceso de una representación liberal del Estado moderno, abierto en teoría al conjunto de las demandas provenientes de la sociedad civil. La crítica más virulenta de esta representación fue conducida por autores marxistas que vincularon la crisis del Estado a las transformaciones del capitalismo (Brunhoff et al., 1976);

- la confianza aun en lo político, en su capacidad para tratar el conjunto de los problemas de las sociedades modernas, y la aparición de una sociedad civil cada vez más reivindicadora en términos de organización del poder (Keane, 1998);

- la fragmentación de los sistemas decisionales tras la modificación de la estructura interna de los Estados, a causa de las reformas descentralizadoras de las dinámicas federalistas (Loughlin, 2001);

- la critica de una manera de toma de decisiones basada en la representación política (luego entonces, sobre el carácter central del representante político elegido) y en el predominio de 
la evaluación científica que era ostentada por las administraciones, ahora refugiada detrás del monopolio de la técnica (Callon et al., 2001);

- la consolidación de nuevos territorios de acción colectiva, en particular, la metrópolis en el seno de la cual los movimientos sociales, a partir de los años 70, fueron sujetos a una integración política "desde arriba" (Hamel et al., 2000a);

- $\quad$ por último, la redefinición de la ciudadanía, en su traducción liberal y universalista, por grupos sociales que reivindicaban un tratamiento comunitario permitiendo, en su modo de ver, hacer caso omiso de los políticos, que al amparo del liberalismo político, sustentaban la discriminación de grupos dominados (en función de la clase, la lengua, los orígenes étnicos, las prácticas religiosas y la orientación sexual, entre otras) (Beiner, et al., 2001).

En este contexto general fueron poco a poco imponiéndose en la agenda, tanto científica como política, un cuestionamiento del modelo de Estado central de lo político basado en la democracia representativa, así como del peritaje científico no compartido y de la concepción universalista de la ciudadanía como los temas de la democracia local y de la proximidad política: lo local, tomado en su doble dimensión de espacio físico y político (re)deviene el nuevo territorio de referencia de lo político, a partir de lo cual sería posible reconsiderar tanto la actuación sobre la crisis de gobernabilidad de las sociedades modernas como las soluciones al conjunto de la problemática mencionada anteriormente. Es necesario tener en cuenta que esta dinámica no tiene el mismo alcance en los contextos políticos nacionales. En los Estados Unidos, de hecho, se trata de una característica principal de la construcción del Estado-nación en la cual lo local es a la vez sinónimo de proximidad política, de democracia eficaz y sobre todo de instituciones alternativas al Estado federal. Por el contrario, en Europa el proceso es más reciente. En los dos casos, lo local es el lugar donde todas las contradicciones sociales, económicas y políticas están presentes. Tiene el estatuto de instancia privilegiada, a partir de la cual es posible garantizar la transición entre la "primera modernidad" que consagró el carácter central de los Estados en la organización política y económica de las sociedades, y una "segunda modernidad" en la era de la globalización, que solucionaría la crisis de instituciones amenazadas por sociedades cada vez más reflexivas (Beck, 1992; Giddens, 1990).

Sin embargo, caeríamos en un error si consideráramos que esta "crisis" afecta al conjunto de lo político, entendido como un sistema que integra a la vez elementos ideológicos, instituciones, actores especializados -los políticos elegidos- y de los ciudadanos (Norris, 1999). En el seno de las sociedades occidentales, hay en efecto un consenso generalizado sobre los valores que representa la democracia liberal. Por el contrario, las instituciones y los actores que se suponen traducen estos valores en actos son sujetos de vigilancia: los partidos políticos y los representantes elegidos concentran el mayor descontento, en distintos grados, según los países (Pharr and Putnam, 2000ÊE; Putnam, 2002). En este contexto el recurso a la democracia participativa a nivel local-sobre todo en medio urbano-es considerada ampliamente como la solución al problema de la desconfianza en la relación con lo político. Esencialmente, esta agenda democrática constituye supuestamente la matriz a partir de la cual podemos refundar sobre nuevas bases el vínculo entre la esfera de lo político y la sociedad civil.

En esencia, lo local parece dar la espalda a la democracia representativa para preferir ahora la democracia participativa y deliberativa. En una perspectiva típicamente tocquevillista (De Tocqueville, 1842), 
la democracia participativa organizada a nivel local, aun si es necesario señalar que trasmite representaciones y discursos diferentes según los Estados y las ciudades (Boudreau, 2003), es evocada, en primer lugar, en las democracias modernas para reconstruir un orden político en plena transición.

Es cierto que la democracia local, fundada sobre el principio de la participación y no solamente de la representación política, desarrolla supuestamente un sentimiento de pertenencia a una comunidad, el compromiso, la generosidad, el sentido de la moralidad, el interés por los asuntos públicos, más allá de los intereses individuales -tanto de virtudes y de "competencias cívicas"- que distinguen la democracia representativa de la democracia participativa (Elkin, et al., 1999). Además, ahora, cuando el lugar del Estado es impugnado cada vez más en la regulación de las sociedades modernas, se reconsideran los alcances de los trabajos de J. S. Mill sobre la democracia local en los Estados Unidos. En su obra Sobre la libertad, J. S. Mill sostiene que el Estado no debe interferir en las decisiones de los ciudadanos, que están en mejor condición de establecer sus opciones conforme a sus expectativas y sus preferencias (Mill, 1859). Con todo, sabemos que esta visión encantada de la democracia local poco resiste a la prueba de los hechos (Bryan, 1999, Mansbridge, 1980).

La cuestión de la participación política se convirtió así en la piedra angular de numerosas políticas locales en Europa y Norteamérica. Este "éxito" debe contarse a partir de la experiencia de Estados Unidos en el "tratamiento" de algunas zonas céntricas de las ciudades con procesos de empobrecimiento acelerado a partir de los años sesenta. Es evidente que en los Estados Unidos la democracia participativa a nivel local fue por primera vez concebida como una herramienta de liberación de grupos sociales dominados.

A partir de los años sesenta, podemos situar el momento en que son expresadas las posturas analíticas que establecían un vínculo entre la democracia local participativa y las relaciones de fuerza entre grupos sociales urbanos (Bachrach, et al., 1975; Kaufman, 1960 ; Pateman, 1970 ). Alimentando la Nueva Izquierda en los Estados Unidos, este análisis se aplica en una serie de programas de acción pública (como el Economic Opportunity Act de 1964, el Model Cities Program de 1966 y el Urban Renewal Project de 1968) conducidos por el Estado federal con destino a la comunidad negra que vivía en el centro de las ciudades. Por medio de medidas que orientaban a esta comunidad específica y a través de la temática del neighborhood government, se trataba de favorecer el compromiso cívico en los barrios desfavorecidos y de permitir el surgimiento -gracias a los procesos de aprendizaje y socialización política que fueron posibles a través de la participación- de una elite política nacida de los grupos desfavorecidos. Al mismo tiempo, se controlaba el proceso de selección para evitar que esta elite no adoptara posiciones juzgadas demasiado radicales o incluso extremistas (Hallman, 1974; Schoenberg et al., 1982). Aplicada en primer lugar en las inner cities de los Estados Unidos, la formula fue objeto después de una exportación en numerosos países europeos.

En este contexto general, lo local y sus instituciones ¿pueden ser los espacios y las arenas de recomposición del orden político sobre una agenda más participativa y deliberativa?

\section{ESPLENDORES Y REALIDADES DE LA DEMOCRACIA LOCAL (PARTICIPATIVA)}

Los resultados provenientes de un gran número de programas de investigación nos dejan por lo menos perplejos. En los hechos, el recurso a la participación, a la consulta de los ciudadanos viene, paradójicamente, a reforzar las características de los sistemas políticos y el carácter cen- 
tral de los representantes elegidos. Cualesquiera que sean los contextos institucionales, la legitimidad de la elección permanece como uno de los fundamentos esenciales del orden político.

La confrontación entre las legitimidades políticas, aquella surgida de la representación política aportada por los ciudadanos se vuelve, muy regularmente, en detrimento de estos últimos. Por otra parte, tal como lo habían mostrado desde el principio de los años ochenta algunos trabajos producidos por investigadores de los Estados Unidos sobre la política federal con destino a las inner cities (Yates, 1982). El tema de la proximidad, de la participación de las asociaciones en las políticas públicas aparece tal cual, es decir, una retórica que oculta mal su finalidad: cambiarlo todo (en el discurso) para que todo quede sin cambios en la jerarquía de las posiciones y de los roles.

Sobre todo, la institucionalización de procedimientos de concertación conduce inevitablemente a una de las paradojas más aceptadas y que limita considerablemente el alcance real de la democracia participativa en cuanto a la transformación del orden político y a la posibilidad de cuestionar los valores dominantes: la obligación del público invitado a la mesa de deliberaciones de respetar las reglas del juego impuestas y fijadas desde el ámbito político.

Además, el lugar del peritaje en la mediación vuelve muy delicada toda verdadera democratización (Blanc, 1999). El "código genético" de estos procedimientos de concertación, de la participación destinada a volver a entablar el vínculo entre la sociedad civil y lo político impide toda expresión del conflicto (Baqué et al., 1999). El apego de la relación del ciudadano a los procedimientos formales de las instituciones limita considerablemente el impacto de la democracia participativa institucionalizada. El manejo de las reglas del juego político es el resultado de un largo proceso de socialización y consagra una asimetría en la constitución del peritaje propiamente político (Edelman, 1991). La democracia participativa a nivel local permite claramente constituirse como tales a las nuevas elites surgidas de la sociedad civil, permitiéndoles comprometerse en un proceso de aprendizaje de nuevas agendas de acción (Lafaye, 2001). Sin embargo, esta democracia está lejos de permitir a los ciudadanos "ordinarios" (Marie et al., 2002) de tener real influencia en sus opciones colectivas. Por lo que se refiere a los grupos sociales dominados, incluso estigmatizados, ella contribuye a su desafiliación con relación al sistema político. En sentido contrario, esta democracia participativa permite la cooptación dentro de la esfera política de los "representantes legítimos" surgidos de la sociedad, así como la aparición de "profesionales" de la participación.

Es en ese sentido como podemos evocar la hipótesis de una consagración de los "notables" locales hecha posible por el ejercicio de la democracia local sobre una agenda institucionalizada. No se trata exclusivamente de los representantes elegidos -que acaparan en su beneficio las instituciones locales-, sino también de los representantes cooptados de la sociedad civil y que actúan -a causa de los recursos cognoscitivos e instrumentales que pueden movilizar- como actores inevitables de la mediación entre la sociedad civil y la esfera de lo político en el nivel local.

Así, incluso si conviene no mitificar las dinámicas en las que se fundamenta la acción colectiva, porque sabemos que enfrentan el reto de la institucionalización por parte de los poderes públicos (Hamel et al., 2000b). Sin embargo, podemos justificar la pregunta de si el alcance de la democracia participativa de "última generación" -en relación con los movimientos sociales urbanos, los más radicales en sus pretensiones- no es meramente simbólico. Igualmente, podemos preguntarnos también si ello no resulta finalmente de un mero ejercicio de comunicación política. 
Sin establecer una respuesta definitiva, se puede considerar, sin embargo, que la institucionalización de la democracia participativa en las políticas locales, al amparo del resurgimiento de la relación con lo político y de la búsqueda de nuevas formas de gobernanza, conduce, finalmente, a poner a los representantes elegidos en el centro de la regulación política y, sobre todo, a limitar considerablemente todo cuestionamiento del orden político local y de los valores que se vinculan a él.

En efecto, la institucionalización de la participación democrática plantea como cuestión fundamental la delimitación del sistema de acción. La relación de fuerza se construye en torno al reconocimiento, a partir de lo político, de algunos actores dotados del status funcional de "representantes" de la sociedad civil. Una vez resuelta esta cuestión, que nos conduce a ver actuar estos "representantes" en el campo de lo político -y ver cómo respetan sus normas, en materia de interacción, de jerarquía en particular-, podemos concluir que esta forma de democracia deja solo un pequeño espacio al cuestionamiento de esa misma jerarquía, así como de los valores que estructuran sus opciones colectivas.

La democracia local, en su versión institucionalizada, no aparece con este título como una forma de expresión que permite el procesamiento de las opciones colectivas estructuradas, sobre todo por el campo de lo político. Según esta hipótesis, con la convocatoria de los representantes elegidos al banquete de la democracia local participativa e institucionalizada, los actores provenientes de la sociedad civil participan así, muy a su pesar, en la reproducción del orden político.

De allí, notamos una contradicción evidente: lo que se gana en legitimidad en el campo político no parece haber tenido ninguna incidencia sobre la recomposición de la jerarquía política, o sobre la capacidad para incidir en las opciones en el seno de este campo. El pluralismo político, a través de la apertura formal de los sistemas de toma de decisión, no conduciría necesariamente a una interrupción del orden político.

Otra problemática esencial que se discute en torno a la democracia participativa es: ¿qué tipo de espacio se puede utilizar razonablemente en esta agenda? En un contexto caracterizado por la potenciación de las ciudades, de las instituciones de la aglomeración, ¿es posible organizar esta agenda democrática en una escala supramunicipal? En efecto, ¿cómo concebir el ejercicio de la democracia participativa eficaz en una escala metropolitana, mientras que es ya complejo aplicarla a escala barrial que, desde los años setenta, se considera como el espacio esencialmente más adaptado a la participación, a la deliberación (Kotler, 1969)?

Incluso los más ardientes partidarios de la tesis de la refundación del vínculo entre la esfera de lo político y la sociedad sobre la base de la participación política en el ámbito metropolitano no responden aún esta pregunta. La escala de referencia de la democracia local, aun cuando se desarrolla en el ámbito metropolitano, sigue siendo el barrio y aún más, el municipio (Berry et al., 1993). Por otra parte, es precisamente en nombre del respeto a la democracia local que ciertos procesos secesionistas conducen a algunos municipios a "separarse" por medio del referéndum de las instituciones metropolitanas. Estos procesos están actualmente en boga en Norteamérica y recientemente en Europa occidental (Boudreau et al., 2001; Keil, 2000).

Todo cambio de escala territorial en la organización de la democracia local hacia el nivel metropolitano parece traducirse en el retorno a la representación política como principio de la suma de preferencias. Incluso a la hora de la e-democracia, los cenáculos limitados de Platón y Aristóteles -que consideraban que la democracia no podía desarrollarse eficazmente sino en instancias que 
agrupaban a lo sumo 5.040 individuos o en las cuales la palabra de uno podía oírse distintamente por el conjunto de los otros participantes ${ }^{1}$-, constituyen aún los cuadros territoriales y organizativos insuperables de esta democracia participativa.

\section{LA DEMOCRACIA METROPOLITANA COMO INSTRUMENTO DE ADAPTACIÓN A LA GLO- BALIZACIÓN}

La posibilidad de reconstruir el vínculo político -a través de una transformación de los mecanismos de gobernanza, en el sentido del pluralismo político y del cuestionamiento del carácter central de los representantes locales elegidos- parece así atravesada por un conjunto de contradicciones y de ambigüedades actualmente insuperables. Es lo que vuelve toda evaluación de la democracia local relativamente paradójica: entre los deseos explícitos de los actores y su traducción en actos, el desfase es a menudo muy evidente (Blondiaux et al., 1999).

En sentido contrario, existe una problemática a través la cual esta doble evolución, a priori, parece terminar: aquella que se refiere a la adaptación de las ciudades a la globalización de los intercambios y a la apertura del campo de la decisión en materia de desarrollo económico a los protagonistas de la sociedad civil.

La literatura relativa a esta cuestión es abundante como para que podamos ir al detalle (Cox, 1997; Johnston et al., 2002; Sassen, 2002). A partir de los años ochenta, resultó evidente que una de las transformaciones principales del capitalismo que siguieron al doble shock petrolero de los años setenta y al ahogo del fordismo en los países desarrollados, se refería al papel respectivo de las metrópolis y de los Estados. Desde hace treinta años, esta transformación condujo a una nueva división del trabajo entre las instancias oficiales y las metrópolis; la cuestión del desarrollo económico no era ya monopolio del Estado únicamente, ahora representaría cada vez más una función, una competencia compartida.

¿Cómo vincular esta evolución funcional y el recurso cada vez más frecuente de la participación de los actores de la "sociedad civil"? En el marco de una lectura tomada claramente de la economía política y la escuela de la regulación, el capitalismo -definido como un régimen de acumulación característico de un período histórico dado- aparece aquí continuamente cuestionado por sus contradicciones, sus tensiones y sus antagonismos internos. Este capitalismo requiere, para reproducirse y transformarse, un conjunto de mecanismos de regulación fundados sobre normas, leyes, compromisos institucionalizados que instalan los conflictos sociales en marcos espaciotemporales rutinizados, estabilizados (Lipietz, 1996).

Sin embargo, los elementos de esta regulación, en particular su sujeción espacial, no son estables en el tiempo:

debido a su dinamismo, el capitalismo vuelve obsoleta continuamente la base geográfica que crea, a partir de la cual se reproduce y se desarrolla. Muy especialmente durante las crisis sistémicas, los marcos territoriales heredados pueden ser desestabilizados en la medida en que el capitalismo supera las infraestructuras socio espaciales y los sistemas de relaciones de clase que no proporcionan más una base segura para una acumulación duradera (Brenner et al., 2002 : 7).

Citado por Berry, Jeffrey M., et al. 1993. The Rebirth of Urban Democracy. Washington: The Brookings Institution. 
El Estado, más concretamente el Estado Benefactor de tipo keynesiano, fue durante los "Treinta Gloriosos" la instancia y el territorio central de la regulación. Las recientes transformaciones del capitalismo cuestionaron este carácter central del Estado en el proceso de regulación. Es en este marco donde es necesario comprender el proceso de recomposición política, traducido en el hecho que el Estado, más concretamente su territorio y sus instituciones, no tiene ya el monopolio de la regulación política de las sociedades modernas. Así, la regulación puede considerarse como el conjunto de las actividades políticas que permiten el arbitraje de los conflictos entre grupos sociales, la instauración de lo político redistributivo entre estos grupos sociales, la producción de identidades colectivas localizadas y la difusión de una ideología dominante.

De esta forma, la definición de territorios "pertinentes" para que esta regulación se reposicione a la vez por el enjeu (lo que esta en juego) central de las relaciones entre el Estado y la sociedad civil, pero, dentro de esta última, entre grupos sociales. La literatura de lengua inglesa relativa a la political rescaling insiste muy claramente sobre este elemento central: la reterritorialización de la acción pública no responde solamente a imperativos de la gestión y funcionales, sino que constituye uno de los elementos esenciales de la transformación de la regulación política de las sociedades occidentales (Cox, 1998b). Esto nos plantea la cuestión del nivel territorial a partir del cual son tratadas la justicia social, la producción de identidades colectivas y la difusión de la ideología dominante. ¿Si la comunidad política no se confunde más con el Estado-Nación, donde se la puede situar?

No se trata de una problemática propiamente teórica. En ella está el fundamento de las luchas y de las tensiones que estructuran el campo político, tanto que queda es claramente establecido que toda nueva reestandarización política produce oportunidades y costes muy diferentes, según los grupos sociales (Brenner, 2000; Cox, 1998a). Como lo advierte E. McCann,

las políticas que enmarcan los cambios contemporáneos en los procesos de toma de decisiones en el ámbito urbano son políticas de escala. En estas políticas, la escala no es sino un simple receptáculo. Es un marco discursivo utilizado por grupos en competición con el fin de definir o redefinir la localización más apegada a sus intereses de poder político y el marco territorial de políticas y mecanismos de regulación específicos (McCann, 2003:166).

La participación política es uno de los vectores de esta recomposición, ya que se inscribe, como práctica, en territorios políticos delimitados o en construcción. Desde el ángulo de la economía política, las ciudades se convierten en los cuadros territoriales a partir de las cuales se opera una nueva regulación del capitalismo, es decir, de los espacios en los cuales, por una parte, las contradicciones del capitalismo se desplazan y se territorializan y, también, en el seno de las cuales son necesarios nuevos compromisos. La regulación urbana integra, finalmente, una dimensión ideológica muy importante, en el sentido de A. Gramsci: la vida cotidiana en la ciudad, es cuando el urbanismo y las instituciones urbanas devienen vectores importantes en el objetivo de obtener la legitimación el neoliberalismo (Keil, 2002; Kipfer et al., 2002).

Esta adaptación al neoliberalismo no es solamente en el caso de la esfera de lo político, stricto sensu. En efecto, esta conversión se encuentra incluso en algunos segmentos de la sociedad civil. Rescatando de aquello que consideramos como la política de habilitación (empowerment), esta forma de desarrollo económico es, por numerosos aspectos, innovadora. 
Ella se nutre con una crítica bastante fuerte de las formas de intervención articuladas al keynesianismo y al Estado Benefactor, incapaces de solucionar los problemas sociales y económicos de algunos barrios y ciertas comunidades donde la historia estuvo vinculada a la dominación que siguió a la crisis del fordismo. A la vez se ha visto como un conjunto de relaciones de producción internas a las empresas y, más generalmente, como un conjunto de relaciones sociales de clases, de géneros, étnicas y raciales. Esta perspectiva es alimentada en gran medida, en términos analíticos, por el concepto de capital social, definido como el conjunto relaciones sociales basadas en la confianza, la reciprocidad, el altruismo que caracterizan a un grupo social dado y que permite a los actores que forman parte del mismo actuar juntos más eficazmente en la búsqueda de objetivos compartidos (Putnam, 2000).

Es entonces tentador considerar que estas movilizaciones colectivas localizadas en los barrios con dificultades pueden constituir una forma particular del desarrollo local, como una alternativa al control por parte del Estado o por parte de las empresas privadas. Las políticas de habilitación descansan en gran parte sobre esta lógica encaminada a responsabilizar a los actores asociativos y comunitarios locales, a ayudarlos en la formulación y la aplicación de programas adaptados a la especificidad de su territorio. Esta lógica se encuentra también en toda la ornamentación que rodea la transformación del Estado Benefactor y en el desarrollo de la democracia participativa: una relativización del peso de los representantes elegidos, una valorización de los actores locales no surgidos de la esfera política, la definición del bien común por la sociedad civil misma, la alteración de la relación de la soberanía entra el Estado y la sociedad civil.

Por una extraña paradoja, el liberalismo parece constituir un terreno de acción colectiva de pleno derecho para los movimientos sociales generalmente propensos a oponerse a éste. Esto contradice así a B. Barbera, para quien el liberalismo limita toda afirmación de una comunidad y, en particular, toda participación política que refuerce a esta comunidad como "fuerza moral" (Barber, 1997 : 26). Sobre el fondo de la crisis de lo político y de la desconfianza cada vez más expresa en cuanto a la capacidad del liberalismo para solucionar los problemas sociales, esta alternativa es, al menos, seductora. Así, este "modelo" de desarrollo está ampliamente sostenido por instituciones internacionales como el Programa de las Naciones Unidas para el Desarrollo (Programme des Nations-Unies pour le Développement, 2002). Como referencia de la acción está también presente en el Banco Mundial, además del Fondo Monetario Internacional, que pretende integrar incluso otros actores de la sociedad civil y de las organizaciones no gubernamentales en la aplicación de sus programas.

Por lo tanto, podemos preguntarnos sobre el alcance de las transformaciones inducidas por este modelo alternativo de desarrollo local que se basa en la participación de la sociedad civil:

- En primero lugar, los trabajos más recientes sobre los regímenes urbanos en América del Norte y en Europa occidental hacen hincapié en la importancia de "efectos de localidad", de configuraciones institucionales particulares, de culturas políticas territorializadas en cuanto al "éxito" de las políticas de habilitación (Savitch et al., 2002) .

- En segundo lugar, ¿la habilitación conduce a una verdadera transformación de la relación entre la sociedad civil y el Estado? Ciertamente, el Estado no es ya el director exclusivo del desarrollo (o de cualquier otra política). Sin embargo, el Estado continúa teniendo el control 
del mismo, en particular concediendo o negando recursos financieros indispensables para los actores de la sociedad civil. Entonces, hay en ello una notable transformación del papel del Estado, que pierde su carácter central aparente, pero que conserva un papel esencial en la estructuración de los sistemas de acción. Entonces, la habilitación solo es viable en las situaciones donde los actores que representan a la sociedad civil son ampliamente apoyados por las autoridades públicas. Para reanudar la distinción de C. Stone, las autoridades públicas pudieron haber perdido el "poder sobre" las políticas urbanas, pero guardaron el "poder de" estructurar la acción colectiva (Stone, 1989).

- En tercer lugar, podemos incorporar la crítica de B. Jessop, para quien esta movilización de la sociedad civil, a través de su participación activa en las políticas locales, se inscribe también en la transformación del régimen de acumulación y del método de regulación que caracterizan al capitalismo actual. El "neocomunitarismo" -que se refiere esencialmente a los grupos sociales dominados- constituye para este autor una estrategia de adaptación de las metrópolis al neoliberalismo, transformando su agenda de acción y los roles sociales y políticos de sus actores que emanan de la sociedad civil: se convierten en agentes económicos sobre quienes pesa la responsabilidad de su propio destino, en lugar de provenir de las instancias estatales (Jessop, 2002).

Sobre esta agenda de la participación de la sociedad civil en las políticas destinadas a adaptarse a la globalización de la economía y a la competición territorial, conviene ser prudente. La apertura de los sistemas de toma de decisiones es real, las políticas de desarrollo económico se basan en lógicas de movilización colectiva, de creación de recursos mutualizados. Con ello, las configuraciones institucionales cambiaron, innegablemente. Aunque, por otra parte, no se trata solamente de una cuestión de forma sino del contenido de las políticas. El objeto real de todo ello es un cuestionamiento del Estado Benefactor que legitimó durante más de 30 años, e hizo posible el fordismo. Sin duda, la participación de la sociedad civil en las políticas de desarrollo económico a través de la habilitación nutren este cuestionamiento en tanto que no se prueben sus efectos sobre la reducción de las disparidades sociales y la desaparición de la under class (DeFilippis, 2001; Fraser et al., 2003; Perrons et al., 2003).

Sin embargo, los mecanismos de cohesión, de justicia social que estaban centrados en el Estado Benefactor permanecen aún poco precisos; el nivel metropolitano no constituye un territorio de redistribución realmente alternativo al Estado. La reterritorialización política es, entonces, un proceso en curso, no estabilizado, ya que el conjunto de funciones que contribuían a la regulación política de las sociedades no fueron completamente transferidas del Estado hacia nuevos territorios políticos. No se trata ya de una lectura que pone de antemano la tesis del "Estado vacío". Sin embargo, esta reterritorialización es real y conduce particularmente a la transformación de la ciudadanía proceso que se opera a través de la participación política en las políticas locales, sobre todo en el medio urbano. El Estado keynesiano se basaba en la instauración de mecanismos redistributivos entre las clases sociales. El "proyecto hegemónico" (Jessop, 1995) que se construye sobre las cenizas de esta forma estatal descansa, por su parte, en mecanismos de reconocimiento de tipo comunitarista. Ya no está centrado solamente en el Estado sino se sitúa en las ciudades, que son por definición los espacios de la diversidad cultural, y en las instituciones, que se convierten en arenas de primera importancia. 


\section{CONCLUSIÓN: LA CIUDADANÍA URBANA Y LA TRANSICIÓN HACIA LA "SEGUNDA MODERNIDAD"}

El repliegue cívico, la desafiliación partidaria, la versatilidad del electorado, la caída del militantismo, el ascenso de la abstención en las elecciones generales constituyen otras tantas señales de lo que se llama "crisis de lo político". Al menos de una determinada forma de lo político centrado en las instituciones públicas y partidarias cuyos orígenes se remontan al siglo XIX. La democracia representativa organizada sobre un modelo de Estado central genera a la vez escepticismo, protesta y cada vez más comportamientos políticos radicales.

El conflicto del orden político pasa también por el cuestionamiento, de parte de algunos grupos, de los fundamentos de la ciudadanía en su versión universalista. El contraproyecto es de orden "pluralista-identitario-minoritario", para retomar el trinomio de M. Gauchet (Gauchet, 1998). Es aquí donde se incorporan a la cuestión los mecanismos de cohesión y justicia social actualmente en curso de redefinición. En su definición keynesiana, eran los Estados sobre los cuales se centraba la regulación política global de las sociedades modernas quienes expedian la nomenclaturas (cargos), identificaban a los grupos sociales en función de sus "derechos-creados" (Schnapper et al., 2000). Sobre la base de una concepción universalista de la ciudadanía, los Estados extendieron progresivamente estos derechos que garantizaban la cohesión y la justicia social entre los ciudadanos que integraban una misma comunidad política.

Ahora bien, el debilitamiento del Estado keynesiano se acompaña de una movilización cada vez más fuerte de grupos sociales que hacen valer su particularismo (de clase, religión, lengua, etc.). Del mismo modo, se advierte un cuestionamiento de una forma de ciudadanía pasiva basada en la definición, por los grupos dominantes, de estatutos y derechos garantizados por el Estado, hacia una ciudadanía activa en la cual los grupos dominados hacen el proceso de estas nomenclaturas (Isin, 2003).

Esta dialéctica de la universalidad y el particularismo nutre una nueva forma de ciudadanía en formación. Las ciudades representan los espacios privilegiados de conflicto del orden social y político por los grupos dominados que no disponen siempre de los derechos cívicos (libertad de palabra, movimiento, asociación, no discriminación, etc.), políticos (derecho de voto y derecho a presentarse a las elecciones) y sociales (políticas redistributivas conducidas por los Estados) asociados a la ciudadanía tanto como con las definidas por los Estados (Sassen, 2000).

La ciudadanía urbana remite pues a procesos políticos radicales que se traducen bajo una forma comunitaria, en contradicción con la definición universalista anterior. No son definidos en relación con un conjunto de instituciones que se confunden con el Estado, ya que, básicamente, se enfrenta este último a la decadencia de la institución que acompaña la "modernidad tardía" (Dubet, 2002 : 372).

Este análisis lo encontramos en los trabajos de U. Beck, que menciona un "desfase institucional". Para este autor, es la equivalencia establecida en la "primera modernidad" entre "la política y el Estado, entre la política y el sistema político" lo que se cuestiona: "el lugar y el objeto de la definición del bien común, la garantía de la paz social y de la memoria histórica son buscados menos dentro que fuera del sistema político" (Beck, 1998 : 23).

Este "segunda modernidad" en la base de una transformación de la ciudadanía, de la cohesión y de la justicia social, se desarrolla actualmente en las metrópolis, teniendo por entorno el reconocimiento de la dignidad de los individuos y de su comunidad de pertenencia (Tully, 1995). 
La principal evolución resulta del hecho que los Estados no son las únicas arenas en el seno de las cuales estas demandas se desarrollan. Las ciudades ciertamente han sido los terrenos privilegiados de los movimientos contestatarios, más o menos radicales. Progresivamente, se transformaron en espacios políticos en el seno de los cuales las acciones colectivas que cuestionaban las políticas nacionales se presentaban en nombre de valores "alternativos", "progresistas" (Clavel, 1986; Magnusson, 1996). Actualmente, es la relación con la ciudadanía lo que está en juego.

Las instituciones urbanas son consideradas debido a su porosidad con relación a las evoluciones empresariales y su función de legitimación de procesos comunitaristas. Esa porosidad es, en particular, hecha posible por los procedimientos de participación política. Entonces, a partir de este reconocimiento -o de su negación- podemos identificar los diferentes regímenes de ciudadanía (Jenson et al., 1996). Estos regímenes otorgan o prohíben la posibilidad a las comunidades de ser formalmente reconocidas como grupos y ser el objeto de un tratamiento particular por parte de las autoridades públicas a causa de su identidad, definida, entre otras cosas, sobre la base de la clase, las prácticas religiosas, la raza, la lengua, las orientaciones sexuales.

Por tanto, no se podría deducir de estas tendencias una pérdida total de la centralidad de los Estados en el proceso de transformación de la ciudadanía. Estas tendencias siguen siendo principales, en particular a causa de su capacidad y eficacia, de su ideología, en la construcción de regímenes de ciudadanía. Por ejemplo, la situación en cuanto al multiculturalismo es muy diferente en Canadá que en Gran Bretaña y Francia, casos especialmente ilustrativos: Canadá y Francia ocupan dos posiciones diametralmente opuestas. El régimen canadiense es claramente multiculturalista, lo que, por otra parte, funda la personalidad y la identidad política del país (Kymlicka, 2003). El régimen británico integra cada vez más elementos comunitarios aun cuando los actores locales pretenden muy a menudo establecer reglas mínimas de corte universalista. Como lo muestra la reciente legislación en la que se prohíbe portar de manera ostensible todo signo religioso en las escuelas públicas.

El régimen francés permanece instalado en una concepción republicana y universalista de la ciudadanía, que no reconoce formalmente ningún derecho particular a individuos por causa de su pertenencia a comunidades específicas. Con todo, algunos autores sugieren la hipótesis de una tendencia en el mediano plazo hacia un "republicanismo moderado" (Jennings, 2000) que encontrará en las políticas urbanas, a través de la participación, un vector esencial de concretización.

Para resumir al extremo el contenido de este artículo, las prácticas participativas a nivel local no permiten una verdadera transformación del orden político, sino que tienden más bien a reforzar las características preexistentes de los distintos sistemas políticos, consagrando el papel central de los representantes elegidos. En cambio, estas formas de renovación de la política se integran en el marco global de la transformación del capitalismo y permiten a este último reproducirse en la escala urbana, en asociación con los grupos sociales desfavorecidos que tienen una ilusión de poder controlar los procesos de dominación de un orden económico que se expresa a la vez en el nivel global, nacional, regional y de las metrópolis.

No obstante, algunos de estos instrumentos participativos son portadores de una nueva concepción de la ciudadanía definida por los grupos sociales marginados, que son objeto de procesos de estigmatización. Esta redefinición no se opera sobre una base no universalista, pero si comunitaria. En ese sentido, la "cuestión urbana" de Manuel Castells se alimentaba y encontraba soluciones 
en el interior de los relaciones de producción (Castells, 1972); la "cuestión metropolitana" reúne esta dimensión añadiéndole la redefinición de la ciudadanía a modo de categoría.

La reterritorialización política que caracteriza a las sociedades occidentales se refiere también a esta transformación de la ciudadanía en medio urbano a causa de la diversidad cultural que caracteriza a la "Gran ciudad" y que en realidad es un objeto sociopolítico particular (Simmel, 1989).

No obstante y paradójicamente, si nos referimos a una buena parte de la literatura sobre la gobernanza, ésta no está centrada tanto en la problemática de la recomposición del orden político, y menos en el lugar de los representantes elegidos; lo que está en primer nivel de atención es la representación política que está en el centro de la discusión actual. Los grupos sociales que abastecen esta dinámica comunitaria (inmigrantes, feministas, minorías lingüísticas, religiosas, etc.) se adaptan muy bien al principio de la representación política; quieren precisamente que este principio se les aplique con el fin de ser parte integrante del sistema político.

Las ciudades y las instituciones políticas que son constituidas en este marco son los vectores privilegiados para estos grupos. Queda por saber precisamente cómo "reaccionan" estas instancias políticas a dichas pretensiones. ¿Por qué y cómo algunos grupos tienen acceso, y otros no, a dichas instancias? Resta también considerar si la selección del personal político sobre la base de la pertenencia de algunos de sus miembros a grupos calificados de minoritarios tiene impactos en el contenido de las políticas públicas.

Sabemos por ejemplo que en Bélgica, el Reino Unido, Francia y en las metrópolis canadienses como Montreal, los representantes políticos de las minorías resultantes de la inmigración se funden fácilmente en el mainstream en las instituciones locales. Una vez elegidos, su orden del día no difiere de la de sus homólogos que vienen de los grupos mayoritarios (Crowley, 2001; Geisser, 1995; Geisser et al., 2001; Simard, 2003 ). Este proceso de alineación de las pretensiones en las instancias democráticas traduce la importancia de las separaciones sobre todo socioeconómicas en las democracias liberales y los efectos de métodos de escrutinio que favorecen la lealtad a los partidos y a las formaciones políticas.

Así, el resultado de la observación de estos grupos no puede, sin embargo, generalizarse al conjunto de los grupos que defienden posiciones comunitarias. Además, no hay que olvidar a los movimientos sociales portadores de estas mismas aspiraciones y cuyo alcance, en términos de transformación de los valores que estructuran a nuestras sociedades, es seguramente más importante. Hay, pues, lugar para un programa de trabajo comparativo que trate sobre la diversidad en las metrópolis insertadas en regímenes políticos, que tienen como fundamento el liberalismo, pero que ofrecen "estructuras de oportunidad" (Kriesi et al., 1992) muy diferentes en cuanto a la consideración y a la gestión política de la diversidad cultural.

\section{REFERENCIAS}

Bachrach, Peter, et al. 1975. "Les deux faces du pouvoir". En Le pouvoir politique, editado por P. Birnbaum. Paris: Dalloz, 61-73. Baqué, Marie-Hélène, et al. 1999. "L'espace public dans les quartiers populaires d'habitat social”. En Espace public et engagement politique, editado por C. Neveu. Paris: L'Harmattan, 115-148.

Barber, Benjamin R. 1997. Démocratie forte. Paris: Desclée de Brouwer.

Beck, Ulrich. 1992. Risk Society:Towards a New Modernity. London: Sage Publications. 
Beck, Ulrich. 1998. "Le conflit des deux modernités et la question de la disparition des solidarités”. Lien social et politiques 39: $15-25$.

Beiner, Ronald, et al. 2001. Canadian Political Philosophy: Contemporary Reflections. Oxford: Oxford University Press. Berry, Jeffrey M., et al. 1993. The Rebirth of Urban Democracy. Washington: The Brookings Institution.

Blanc, Maurice. 1999. "Participation des habitants et politique de la ville". En La démocratie locale. Représentation, participation et espace public, editado por L. Blondiaux, et al. Paris: PUF, 177-196.

Blondiaux, Loïc, et al. 1999. "La politique locale à l'épreuve de la démocratie". En Espace public et engagement politique, editado por C. Neveu. Paris: L'Harmattan, 17-82.

Blondiaux, Loïc, et al. 2002. "L'impératif délibératif". Politix 57: 17-36.

Boudreau, Julie-Anne. 2003. "Questioning the Use of 'Local Democracy' as a Discursive Strategy for Political Mobilization in Los Angeles, Montreal and Toronto". International Journal of Urban and Regional Research 27 (4): 793-810.

Boudreau, Julie-Anne, et al. 2001. "Seceding from Responsibility? Secession Movement in Los Angeles". Urban Studies 38 (10): 1701-173.

Brenner, Neil. 2000. "The Urban Question as a Scale Question: Reflections on Henri Lefebvre, Urban Theory and the Politics of Scale". International Journal of Urban and Regional Research 24 (2): 361-378.

Brenner, Neil, et al. 2002. "Cities and the Geographies of "Actually Existing Neoliberalism". En Spaces of Neoliberalism, editado por N. Brenner, et al. Oxford: Blackwell, 2-32.

Brunhoff, Suzanne de, et al. 1976. La Crise de l'Etat. Paris: Presses Universitaires de France.

Bryan, Frank M. 1999. "Direct Democracy and Civic Competence: the Case of Town Meeting". En Citizen Competence and Democratic Institutions, editado por S. L. Elkin, et al. Philadelphie: The Pennsylvania State University Press, 195-223.

Callon, Michel, et al. 2001. Agir dans un monde incertain: essai sur la démocratie technique. Paris: Seuil.

Castells, Manuel. 1972. La question urbaine. Paris: François Maspéro.

Clavel, Paul. 1986. The Progressive City: Planning and Participation (1969-1984). New Brunswick: Rutgers University Press. Cox, Kevin R. 1997. Spaces of Globalization. Reasserting the Power of the Local. New York: The Guilford Press.

Cox, Kevin R. 1998a. "Representation and power in the politics of scale". Political Geography 17(1): 41-44.

Cox, Kevin R. 1998b. "Spaces of dependence, spaces of engagement and the politics of scale, or: looking for local politics". Political Geography 17 (1): 1-23.

Crowley, John. 2001. "La 'désethnicisation de la représentation minoritaire au Royaume-Uni”. Migrations Société 13 (77): $131-142$. Crozier, Michel, et al. 1975. The Crisis of Democracy. New York: New York University Press.

De Tocqueville, Alexis. 1842. De la démocratie en Amérique. Paris: Gosselin.

DeFilippis, James. 2001. "The Myth of Social Capital in Community Development". Housing Policy Debate 12 (4): 781-806.

Dubet, François. 2002. Le déclin de l'institution. Paris: Seuil.

Edelman, Murray. 1991. Pièces et règles du jeu politique. Paris: Seuil.

Elkin, Stephen L., et al. 1999. Citizen Competence and Democratic Institutions. Philadelphie: The Pennsylvania State University Press.

Fraser, James C., et al. 2003. "The Construction Of The Local And The Limits Of Contemporary Community Building In The United States". Urban Affairs Review 38 (3): 417-445.

Gauchet, Marcel. 1998. La religion dans la démocratie : parcours de la laïcité. Paris: Gallimard.

Geisser, Vincent. 1995. "Des élus d'origine maghrébine dans les conseils municipaux: une avancée ambiguë pour la démocratie locale". En Etranger et citoyen. Les immigrés et la démocratie locale, editado por B. Delemotte, et al. Paris: L'Harmattan, 35-44.

Geisser, Vincent, et al. 2001. "Les personnes d'origine étrangère dans les assemblées politiques belges". Migrations Société 13 (77): 41-55.

Giddens, Anthony. 1990. The consequences of Modernity. Stanford: Stanford University Press.

Habermas, Jürgen. 1997. Droit et démocratie : entre faits et normes. Paris: Gallimard.

Hallman, Howard H. 1974. Neighbourhood Government in a Metropolitan Settings. London: Sage.

Hamel, Pierre, et al. 2000a. Urban Movements in a Globalising World. London: Routledge. 
Hamel, Pierre, et al. 2000b. "Repenser les défis institutionnels de l'action collective". Politique et sociétés 19 (1): 3-18.

Hermet, Guy. 2004. "Un régime à pluralisme limité? A propos de la gouvernance démocratique”. Revue française de science politique 54 (1): 159-178.

Isin, Engin I. 2003. Being Political. Genealogies of Citizenship. Minneapolis: University of Minnesota Press.

Jennings, Jeremy. 2000. "Citizenship, Republicanism and Multiculturalism in Contemporary France". British Journal of Political Science 30 (4): 575-598.

Jenson, Jane, and Susan D. Phillips. 1996. "Regime Shift: New Citizenship Practices in Canada". International Journal of Canadian Studies 14 (Fall): 111-136.

Jessop, Bob. 1995. "Accumulation Strategies, State Forms, and Hegemonic Projects". Environment and Planning A 27 (10): 80-111.

Jessop, Bob. 2002. "Liberalism, Neoliberalism, and Urban Governance: A State Theoretical Perspective". En Spaces of Neoliberalism: Urban Restructuring in North America and Western Europe, editado por N. Brenner, et al. London: Blackwell, 105-125.

Johnston, R. J., et al. 2002. Geographies of Global Change. Malden: Blackwell.

Kaufman, Arnold S. 1960. "Human Nature and Participatory Democracy". En Responsabillity, editado por C. J. Friedrich. New York: Liberal Arts Press, 266-289.

Keane, John. 1998. Civil society : Old Images, New Visions. Stanford: Stanford University Press.

Keil, Roger. 2000. "Governance restructuring in Los Angeles and Toronto: Amalgamation or secession?". International Journal of Urban and Regional Research 24 (4): 758-781.

Keil, Roger. 2002. “'Common-Sense' Neoliberalism: Progressive Conservative Urbanism in Toronto, Canada”. Antipode 34 (3): 578-601.

Kipfer, S., et al. 2002. "Toronto Inc? Planning the Competitive City in the New Toronto". Antipode 34 (2): 227-264.

Kooiman, Jan. 1993. Modern Governance. London: Sage.

Kotler, Milton. 1969. Neighborhood Government: The Local Foundations of Political Life. Indianapolis: Bobbs-Merriel Company. Kriesi, Hanspeter, et al. 1992. "New Social Movements and Political Opportunities in Western Europe". European Journal of Political Research 22 (2): 219-244.

Kymlicka, Will. 2003. La voie canadienne. Montréal: Boréal.

Lafaye, Claudette. 2001. "Gouvernance et démocratie : quelles reconfigurations?" En La gouvernance à l'épreuve de la démocratie, editado por L. Cardinal, et al. Ottawa: Presses de l'Université d'Ottawa, 57-86.

Lipietz, Alain. 1996. "Warp, woof, and regulation: A tool for social science". En Space and Social Theory, editado por G. Benko, et al. Cambridge: Blackwell, 250-283.

Loughlin, John. 2001. Subnational Democracy in the European Union. Challenges and Opportunities. Oxford: Oxford University Press. Magnusson, Warren. 1996. The Search for Political Space: Globalization, Social Movements, and the Urban Political Experience. Toronto: University of Toronto Press.

Mansbridge, Jane J. 1980. Beyond Adversary Democracy. New York: Basic Books.

Marie, Jean-Louis, et al. (edited by) 2002. L'ordinaire : modes d'accès et pertinence pour les sciences sociales et humaines. Paris: L'Harmattan.

Mayer, Margit. 2000. "Urban Social Movements in an era of Globalisation". En Urban Movements in a Globalising World, editado por P. Hamel, et al. London: Routledge, 141-157.

McCann, Eugene J. 2003. "Framing Space and Time in the City: Urban Policy and the Politics of Spatial and Temporal Scale". Journal of Urban Affairs 25 (2): 159-178.

Mill, John Stuart. 1859. On liberty. London: John W. Parker and Son.

Norris, Pippa. (edited by) 1999. Critical Citizens. Global Support for Democratic Governance. Oxford: Oxford University Press. Pateman, Carole. 1970. Participation and Democratic Theory. Cambridge: University Press.

Perrons, Diane, et al. 2003. "Empowerment through Participation? Conceptual Explorations and a Case Study". International Journal of Urban and Regional Research 27 (2): 265-285.

Pharr, Susan J., et al. 2000. Disaffected Democracies: What's Troubling the Trilateral Countries? Princeton, N.J.: Princeton University Press. 
Programme des Nations-Unies pour le Développement. 2002. Rapport mondial sur le développement humain. Approfondir la démocratie dans un monde fragmenté. Bruxelles: De Boeck.

Putnam, Robert. 2002. Democracies in Flux. The Evolution of Social Capital in Contemporary Society. Oxford: Oxford University Press.

Putnam, Robert D. 2000. Bowling Alone: The Collapse and Revival of American Community. New York: Simon \& Schuster.

Sassen, Saskia. 2000. "The Global City: Strategic Site/New Frontier". En Democracy, Citizenship and the City, editado por E. I. Isin. London: Routledge, 48-61.

Sassen, Saskia. 2002. Global Networks, Linked Cities. New York: Routledge.

Savitch, Hank, et al. 2002. Cities in the International Marketplace. The Political Economy of Urban Development in North America and Western Europe. Princeton: Princeton University Press.

Schnapper, Dominique, et al. 2000. Qu'est-ce que la citoyenneté? Paris: Gallimard.

Schoenberg, Sandra Perlman, et al. 1982. Neighborhoods that Work: Sources of Viability in the Inner City. Rutgers University Press: New Brunswick.

Simard, Carolle. 2003. "Les élus issus des groupes ethniques minoritaires à Montréal: Perceptions et représentations politiques. Une étude exploratoire". Politique et sociétés 22 (1): 53-78.

Simmel, Georg. 1989. Philosophie de la modernité. Paris: Payot.

Skocpol, Theda, et al. 1999. Civic Engagement in American Democracy. Washington, D.C.: Brookings Institution Press.

Stone, Clarence S. 1989. Regime Politics: Governing Atlanta (1946-1988). Lawrence: Kansas University Press.

Tully, James. 1995. Strange Multiplicity: Constitutionalism in an Age of Diversity. Cambridge ; New York: Cambridge University Press. Yates, Douglas. 1982. "Neighborhood Government". En Neighborhoods in Urban America, editado por R. H. Bayor. National University Publications: Port Washington, 131-140.

Bernard Jouve es profesor titular de la Cátedra de Investigación de Canadá sobre las dinámicas territoriales en el Departamento de Geografía de la Universidad de Québec en Montreal (UQAM). Actualmente investiga sobre gobierno urbano y territorial en el contexto citadino norteamericano y de Europa occidental. Sus últimas publicaciones son: Local Power, Territory and Institutions in European Metropolitan Regions, London: Frank Cass (con C. Lefèvre) (2002) y La gouvernance urbaine en questions, Paris: Elsevier (2003).

(E-mail: jouve.bernard@uqam.ca) 